\title{
Resenha do livro Ampliando o repertório do coro infanto-juvenil: um estudo de repertório inserido em uma nova estética
}

VERTAMATTI, Leila Rosa Gonçalves. Ampliando o repertório do coro infantojuvenil: um estudo de repertório inserido em uma nova estética. São Paulo: Editora UNESP; Rio de Janeiro: FUNARTE, 2008. R\$34,00.

Débora Andrade (Universidade Federal de S. João del-Rei, São João del-Rei, MG) debora.andrade@ufsj.edu.br

Palavras-chave: coro infanto-juvenil; música vocal; repertório de música contemporânea.

Review of the book Ampliando o repertório do coro infanto-juvenil: Um estudo de repertório inserido em uma nova estética [Expanding the repertoire of the youth choir: a study of the repertorie within in a new aesthetics]

Keywords: youth choir; vocal music; contemporary music repertoire.

Leila Rosa Gonçalves Vertamatti, autora do livro, possui uma sólida formação musical. Ela é Mestre em Educação Musical, Licenciada em Educação Artística, Bacharel em Piano, Composição e Regência e, atualmente, está se doutorando em Música, pelo Instituto de Artes da Universidade Estadual Paulista Júlio de Mesquita Filho.

O livro em questão é fruto de seu mestrado, sendo ele mesmo sua dissertação de conclusão de curso. Ao introduzi-lo, a autora informa ao leitor de forma sucinta sua formação musical, bem como sua inserção no universo da música contemporânea - objeto que inspirou sua pesquisa. E, nesse caso, ela considera como contemporâneas obras do período da história da música em que o sistema tonal vê-se ampliado, surgindo consequentemente novas técnicas composicionais, novidades timbrísticas, utilização de materiais "extraocidentais" e mudanças na maneira como são usadas a voz e os instrumentos. O que motivou Vertamatti à escrita da obra foi a percepção da existência de uma lacuna entre o universo musical contemporâneo e o repertório vivenciado por seus alunos, participantes do CantorlA - grupo que resulta do Projeto "Coros Infantis da UNESP - Educação Musical pela voz", iniciado por Marisa Trench de Oliveira Fonterrada, em março de 1989. O livro questiona ao leitor sobre a possibilidade de se trabalhar a educação musical pela voz na prática de canto coral, aproximando os coristas de uma produção musical que thes apresente outras abordagens estéticas, diferentes da organização tonal.

A fim de colher dados que fomentassem esta reflexão, a autora investigou vários regentes de grupos infanto-juvenis, de São Paulo, percebendo que o repertório utilizado por eles tem ênfase em canções étnicas e na Música 
Popular Brasileira (MPB) e estrangeira. Isto significa que se trabalha apenas parte da linguagem musical, não sendo esta vivenciada em todas as suas modalidades.

Esta reflexão se desenvolve a partir da concepção de música como linguagem, por parte de MERLEAU-PONTY (1975) e de GADAMER (1977). Baseando-se na teoria do primeiro autor, ela acredita que, assim como na língua, o passado de uma música já foi presente e as modificações que ocorrem com o tempo são incorporadas no sistema pela vivência corporal. E, para se compreender as palavras do outro é necessário que sua linguagem seja conhecida. De Gadamer, ela enfatiza que o conhecimento adquirido pelo homem se dá pela linguagem. Uma vez que ele a domina, compreende o mundo. Suas experiências vividas são acumuladas e utilizadas para conhecer fatos presentes. Isto significa que a retenção pela memória de diferentes experiências sonoras permite que o indivíduo reconheça sonoridades familiares que só terão significado se fizerem parte das experiências do sujeito.

Além destes, autores como GUY REIBEL (1984) e MURRAY SHAFER (1991), que propõem uma pedagogia musical próxima da música contemporânea por meio da criação, JOHN PAYNTER (1972), que defende a escuta ativa, SHARON MABRY (2002) e BRIGITTE ROSE (2000), que desenvolvem técnicas específicas para a produção vocal de crianças e jovens, necessárias à execução da música do século $X X$, também, embasam seu trabalho que se desenrola em quatro capítulos, sendo os três primeiros pertencentes à primeira parte, intitulada Os fundamentos e a segunda, capítulo único, intitulada $A$ experiência.

No primeiro capítulo, O Coro infanto-juvenil e seu repertório, Vertamati discorre sobre o trabalho realizado, por alguns corais da Grande São Paulo, que ilustra esse distanciamento do universo musical contemporâneo e a priorização do repertório tonal. Para tal, ela realiza uma observação informal do repertório realizado em 2004 por diferentes grupos corais. Nesta pesquisa, os dados foram coletados nos programas de concerto destes corais e em questionários distribuídos aos regentes pertencentes à Associação de Regentes de Corais Infantis $(\mathrm{ARCl})$. Os dados levantados, em sua pesquisa, reafirmaram o pressuposto da autora de que a maioria dos coros infanto-juvenis de São Paulo possuem uma prática unilateral da linguagem musical, comprometendo o processo educacional, que deveria promover a multiplicidade de experiências musicais para o corista. Os dados revelaram que, dentre as 209 músicas identificadas, $85,92 \%$ delas eram tonais, estando quase $74 \%$ delas em português brasileiro e $81 \%$ acompanhadas por instrumentos, como o piano e 0 violão. Apoiando-se em DOREEN RAO (1987) e em Kodaly, ela justifica o prejuízo pedagógico que esse perfil de repertório promove. Primeiramente, a prática do canto em diversas línguas favorece o desenvolvimento de outros músculos do aparelho fonador, além dos usualmente empregados na fala, e amplia a percepção auditiva, habituando-a à outras sonoridades. Em segundo lugar, a utilização do piano, instrumento temperado, no auxílio do canto entraria 
em conflito com o não temperamento vocal - argumento defendido por Kodaly. Essa unilateralidade da linguagem musical foi principalmente observada nos gêneros musicais apresentados no repertório: $67,41 \%$ das músicas são consideradas populares, 32,33\% étnicas e 9,26\% eruditas. Quase nenhuma pertence ao repertório contemporâneo.

No segundo capítulo, chamado de Transformações: a procura de novas experiências, a autora identifica as principais mudanças ocorridas na linguagem musical, desde a metade do século XIX até 2008, que serviram de subsídio para o trabalho prático da pesquisa. Aqui, ela demonstra o potencial da música contemporânea em ampliar as vivências musicais das crianças, por meio de elementos que não comparecem ou são pouco explorados na prática coral, como as modulações em intervalos de 3as para a mediante, a polirritmia, a polimetria, a aperiodicidade e a assimetria das construções rítmicas, a justaposição melódica, em detrimento da variação, o emprego da harmonia não-funcional, o uso de diferentes organizações escalares, como as escalas octatônica e a dodecafônica, a utilização de clusters, notas pedais, ostinati, bitonalidade, o emprego seriado do ritmo, da intensidade e da duração, a combinação de voz de peito e cabeça, a não utilização do vibrato, característico do bel canto, a inserção de efeitos vocais como risos, assobios, sussurros, suspiros, choros, gritos, estalos de língua, trilos, glissandi e respiração audível. Em seguida, Vertamatti retoma os pensamentos de compositores-educadores que defenderam a aproximação da criança à linguagem contemporânea e conclui o capítulo lembrando ao leitor da necessidade de conviver com as mudanças que ocorrem com o tempo postura que as obras do século XX exigem de seus ouvintes.

Em O Grupo CantorlA e o surgimento do repertório, terceiro capítulo, que encerra a primeira parte, a autora apresenta os ideais pedagógicos e os fundamentos de Fonterrada, na criação do Grupo CantorlA, bem como o trabalho que ali é realizado. Baseada na concepção da música como linguagem já enunciada, Vertamatti propõe uma educação musical, com ênfase na voz, que "priorize a prática e a percepção como meio de transformação do sujeito praticante de música." (VERTAMATTI, 2008, p.63), incluindo no trabalho com o coral infanto-juvenil experiências musicais diversificadas. Neste contexto, o grupo interpretou obras como The Encanteded Forest, de Murray Schafer, Quelques Étoiles Claires, de David Bedford, Plumbas Spes, de Jorge Antunes, Realidarte e Sinestesia, de Alexandre Renche, The Chichester's Psalm, de Leonard Bernstein, Te Deum Puerorum Brasiliae, de Edino Krieger, O Negrinho do Pastoreio, de Eunice Catunda e o musical Edu e a Orquestra Mágica, de Marisa Fonterrada e Heliel Lucarelli. Mas esse rico repertório não se encerra aqui. Há mais uma lista razoavelmente grande de músicas que compõem o repertório do grupo e que será apresentada no quarto capítulo do livro. 
O terceiro capítulo estuda a inserção da música contemporânea no repertório do Grupo CantorlA, assim como as estratégias pedagógicas utilizadas e a reação do grupo ao trabalho realizado.

Este é um capítulo historicamente mais denso, pois a autora relata minuciosamente o processo de construção do repertório, que valorizou a diversidade de linguagens musicais, e que se deu pela interação do projeto com diferentes compositores e regentes, além de destacar a importância, para essa construção, de um estágio realizado por ela, na França, junto à educadora musical e cantora Brigitte Rose, da École Nationale de Musique Du Pays de Montbéliard.

Ao ler o livro, percebe-se que o trabalho de aproximação das crianças com o universo sonoro contemporâneo aconteceu por um processo didático: propuseram-se criar sonoridades vocais que refletisse determinado caráter expressivo, imaginar, desenhar e descrever verbalmente paisagens sonoras e escolher os materiais sonoros que representassem cada elemento contido nelas. Além do ensaio do repertório ter início por obras tonais e, deste universo, ir-se distanciando gradativamente, foram aplicados exercícios propostos por Guy Reibel, no livro Jeux Musicaux (1984).

O quarto capítulo, intitulado "Limpeza de ouvidos", é um capítulo denso e longo, no qual ela descreve todo o rico processo pedagógico demandado por cada música ensinada, cada exercício proposto e a reação do grupo a cada novidade musical surgida. Aqui, Vertamatti informa ao leitor os novos conceitos musicais apreendidos, as habilidades e os conteúdos musicais trabalhados com os coristas, por meio de um repertório nada comum entre os corais infanto-juvenis brasileiros. No repertório apresentado no livro, constam as seguintes obras: Volt nekën ëgy Kecském, de Zóltan Kódaly, O cachorro viralata, de Marisa Fonterrada, Gomb, Gomb, Die Bommel, Pom-pom, Frauenkklatsch, "Pletykázó asszonyok e Tittle-talle, de Gyorgy Ligeti, O navio pirata, de Lindembergue Cardoso, Seis Oraciones op.78b - Oracion I, de Mario Alfaro Güell, Snowforms e Gamelan, de Murray Schafer, Eu e O bicho alfabeto, de Jean-Yves Bosseur, The wonderful widow of the eighteen springs, de John Cage, Ballo, de Luciano Berio, Quand il souffle de l'ouest eles se réfugient à l'est les feuilles tombeés e He! C'est I alune qui a chanté coucou?, de Victor Flusser, Süßer Tod, de Klaus Stahner e Johannes R. Köhler, Wenn der schwer Gedrückte Klagt, de Arnold Schoenberg, Der Glühende"-op.2 n², de Alban Berg, Pequeno nascer, grande morrer, de Álvaro Borges, Little Grey Eyes, de Arthur Rinaldi e Der Nordwind, de Arne Mellnäs. Ufa! Nada mau para um grupo que está apenas dando início à uma vida de experiências musicais! Dentro deste imenso universo musical citado, o grupo experimentou diferentes maneiras de se usar a voz, como a do Sprechgesang, do sussurro, da fala, da fala entoada, do grito, da improvisação vocal e de outros diferentes efeitos vocais. Em relação à leitura, foram trabalhados o ritmo livre, a complexidade rítmica, a combinação de notação gráfica e aproximada, a fragmentação melódica e as mudanças frequentes de compasso. Cantaram cromatismos, 
clusters, glissandi, textura granulada, sonoridade pentatônica, modal, coloração tonal e não tonal e harmonia de quartas. As imagens, trazidas por este capítulo, de desenhos feitos pelos alunos durante as intervenções pedagógicas, ilustram a real apreensão do universo sonoro trabalhado, expressa por meio da grafia livre. Mas criança pode gostar de música contemporânea? Esse não é um universo tão distante do que é veiculado no dia-a-dia de todos nós? A dificuldade em lidar com a linguagem é delas ou nossa (regentes)? Os depoimentos, que encerram este agradável livro, refletem o alcance deste trabalho na vida de alunos que permaneceram no grupo por seis, oito anos e que até se tornaram cantores profissionais, após o egresso.

A experiência pedagógico-musical de Vertamatti revelada no livro junto ao CantorlA é, sem dúvida, muito rica, inspiradora e singular. Como resultado deste trabalho, o grupo foi coroado com apresentações em Amsterdã, em The Bonn International Chorus in Concert e, dentre outros lugares, em workshop na França, sob a regência de Brigitte Rose.

É isto! Uma obra fácil de ser lida, por possuir uma linguagem clara e didática, e agradável! Constitui-se, sem dúvida, numa proposta ousada, ainda mais em relação à realidade coral de determinadas regiões do Brasil, onde essa cultura ainda é incipiente. Mas seu conteúdo nos provoca, enquanto regentes e educadores musicais. Impossível ler a obra sem se sentir, no mínimo, aquém do tempo!

O livro Ampliando o repertório do coro infanto-juvenil: Um estudo de repertório inserido em uma nova estética pode ser adquirido no endereço www.editoraunesp.com.br.

Débora Andrade Débora Andrade possui Mestrado em Música, Especialização em Educação Musical e Bacharelado em Regência pela UFMG. Foi regente dos Corais Infantis do Centro de Musicalização da UFMG (1999-2005), Projeto Cariúnas (2001-2008), Minas Tênis Clube (2005-2009) e Infanto-juvenil da Escola Theodor Herzl (2011 - 2013). Foi professora do Curso de Licenciatura em Música do Centro Universitário Metodista Izabela (2009-2013) e, atualmente, é professora no Departamento de Música da UFSJ (Universidade Federal de São João del Rei), onde coordena o Projeto de Extensão Benke, que visa a expansão dos corais infanto-juvenis na Região das Vertentes. 